\title{
MARKETING DA MARCA: UMA ANÁLISE SEMIÓTICA DO PROCESSO DE CONSTRUÇÃO DAS MARCAS
}

Hélio Silva ${ }^{1}$

\begin{abstract}
Resumo
Este artigo pretende analisar o processo de construção das marcas do marketing contemporâneo. Trata-se de abordar o deslocamento da práxis do marketing subordinado à produção (era industrial) para a práxis do marketing subordinado à esfera cultural. $\mathrm{O}$ mecanismo em que se ancora tal transformação mercadológica é a da substituição das estratégias de persuasão e sedução para aquisição de bens e serviços por um sistema que mercantiliza o acesso a "estilos de vidas" por meio da cultura. Este fenômeno denominamos aqui de arquitetura das marcas.Nossa trajetória de investigação transcorre a partir dos fundamentos semióticos de análise do discurso perpassando pelos conceitos de tecnologização do discurso proposto por Norman Fairclough. Após o desenvolvimento dos conceitos, analisamos o processo de construção das marcas presente no discurso editorial das revistas Carta Capital, Veja, Época e RAE), que fornecerão elementos empíricos das estratégias do marketing contemporâneo.
\end{abstract}

Palavras chaves: Marketing; Comunicação; Marca; Semiótica

\begin{abstract}
In this paper, I anylise the process of brand construction in the marketing and I argue that there has been a shift from the marketing subordinated to production (industrial period) to the marketing subordinated to culture. This transformation is due to the substitution of strategies of persuasion and seduction by those which trade access to "lifestyles". This phenomenon is called brand architecture. The analysis is based upon the semiotic approach of discourse analysis and uses concepts of discourse technologization developed by Norman Fairclough The editorial discourse of some magazines, such as Carta Capital, Caros Amigos, Veja, Época and RAE provides the empirical object for this investigation.
\end{abstract}

Key-word: Marketing, communication, brand, semiotics

\footnotetext{
${ }^{1}$ Hélio Cesar Oliveira da Silva. Doutor em Comunicação e Semiótica pela PUC/SP. Professor/pesquisador do Centro Universitário SENAC.
}

Artigo recebido em Fevereiro e aceito em Maio de 2010.

Revista Administração em Diálogo

Programa de Estudos Pós-Graduados em Administração

Pontifícia Universidade Católica de São Paulo 


\section{Introdução}

Para o marketing, a comunicação é uma atividade atinente à promoção dos produtos ou serviços. Ainda que a comunicação envolva também tais elementos como relações públicas, telemarketing, vendas diretas entre outros o que se observa é a primazia do gerenciamento da informação que, a partir do final do século XX, com o incremento de todo o processo tecnológico comunicacional (multimídia, internet, vídeo-conferência etc) passou a ser o fator determinante na construção do "marketing das marcas". Com este mecanismo a administração mercadológica praticada pelas organizações desloca-se dos princípios econômicos para uma estrutura de construção de identidade por meio do gerenciamento dos valores culturais e sociais.

Para discutirmos os mecanismos de funcionamento do marketing da marca recorreremos aos conceitos da análise semiótica de discurso. A partir das leis que regem o sofisticadíssimo aparato da análise do discurso, tentaremos desvendar o discurso do marketing, valendo-nos de uma análise nos níveis fundamental, narrativo e discursivo, conforme os fundamentos semióticos dados por A. J. Greimas, particularmente sobre a condução do aporte teórico proposto por José Luiz Fiorin, Diana Luz Pessoa de Barros, Jean Marie Floch, Andrea Semprini, sem descuidar de Norman Fairclough, teórico de outra matriz epistemológica - a inglesa - de teoria do discurso.

Após a ilustração das matrizes semióticas da construção das marcas apresentado por Semprini, analisaremos o processo de construção das marcas do editorial das revistas Carta Capital, Veja, Época e RAE (Revista de Administração de Empresas publicada pela Fundação Getúlio Vargas).

Com estas análises e reflexões sobre o marketing da marca pretende-se fornecer pistas dos mecanismos de funcionamento do marketing contemporâneo e os impactos econômicos, sociais e cultuas que este novo modelo promove.

Revista Administração em Diálogo Programa de Estudos Pós-Graduados em Administração Pontifícia Universidade Católica de São Paulo 


\section{O marketing da mercantilização da cultura: conceitos e pressupostos}

Para analisar os dez anos do processo da marca da Citroën, Floch (1993) recorre à análise semiótica dos valores de consumo. Na década de 1980, o autor reconhece na ação comunicativa da Citroën quatro fases: prática, utópica, crítica e lúdica. Esses quatro elementos colaboraram para a produção dos sentidos no processo de sedução e persuasão do consumidor. De um lado, há os valores de uso como valorização prática, ou seja, a funcionalidade dos bens e serviços adquiridos pelos indivíduos: de outro estão os valores de base - o amor, a liberdade, a felicidade, a justiça, a beleza, enfim, os valores considerados universais pela sociedade. $\mathrm{O}$ que se observa é que, de acordo com os elementos socioculturais do repertório do indivíduo, este será mais suscetível a um discurso ancorado em valores de base (valores utópicos ou lúdicos) ou de uso (valores práticos e críticos). Vale lembrar que esse processo não é necessariamente dicotômico; possivelmente o indivíduo possa ser persuadido pelos dois elementos em graus diferentes.

Em síntese, Floch identifica os valores de uso com a valorização crítica e prática, e os de base com a valorização lúdica e utópica. Nessa sistematização, enquanto o valor de uso é pautado na racionalidade, na informação tecnicista e na praticidade, o valor de base apóia-se na utopia e na emoção.

A partir dos conceitos semióticos de Floch, Semprini (1995) propõe o mapeamento dos valores de consumo para analisar marcas, e o faz com empresas como Levi's, Benetton, Renault, Adidas, Danone, Gilette, Total e Philips, entre outras. Por meio do mapa semiótico de valores de consumo, Semprini faz uma minuciosa análise da trajetória da marca Benetton de 1966 até 1991, mostrando os diferentes percursos do processo de sedução impulsionados pelo motor semiótico de produção de sentido. Com as campanhas de marketing, forjaram-se discursos para a construção da identidade da marca,

\footnotetext{
Revista Administração em Diálogo 
perpassando os diversos quadrantes semióticos de valores de consumo: utópico, lúdico, prático e crítico.

O mapeamento 1 apresenta a matriz semiótica do mapeamento dos valores de consumo proposto por Semprini - utópico versus prático e lúdico versus crítico. O utópico e o lúdico são valores de base; o crítico e o prático, valores de uso. As relações entre esses valores (utópico, lúdico, crítico e prático) se dão por oposição ou por sobreposição. De um lado, há um eixo dicotômico entre utópico versus prático e crítico versus lúdico e, do outro lado, entre os mesmos pares há relação de entrecruzamento e sobreposição, como haveremos de ver em nossa análise.

\section{Mapeamento 1 - Mapeamento semiótico dos valores de consumo}

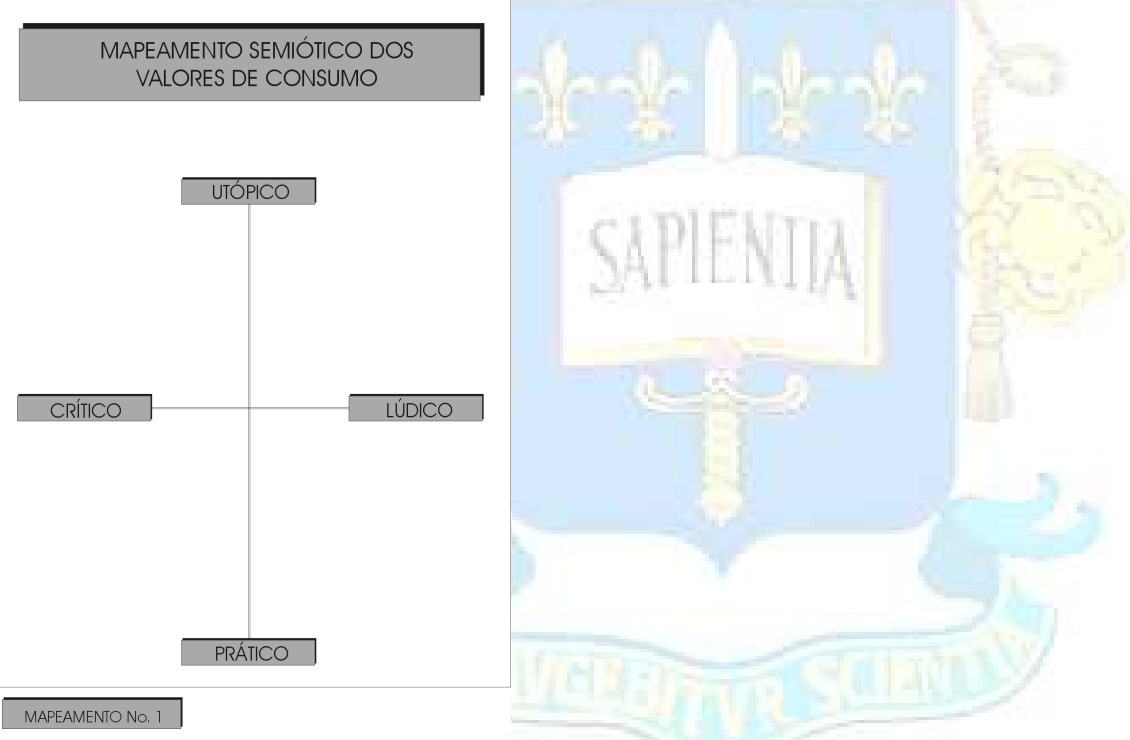

Fonte: Mapeamento semiótico dos valores de consumo (SEMPRINI: 1995, p. 107).

O esquema do mapeamento 1 apresenta os quatros quadrantes que forjam o discurso. Neles, os agentes de marketing definem os elementos (de conteúdo e forma) que produzirão sentidos para os consumidores. Um bem ou serviço poderá ser dotado de 
valores práticos; em conseqüência, terá seu discurso narrativo constituído a partir das características que representam sua funcionalidade e competência técnica. Um bom exemplo de empresas que utilizam esse tipo de recurso está nas pequenas empresas que na grande maioria das vezes comunicam seus produtos e serviços por meio de folhetos, jornais e revistas com descrições técnicas e informações comerciais (forma de pagamento, prazo de entrega, garantia, etc.)

Os valores críticos, por sua vez, apresentam também características dos práticos (racionalidade e funcionalidade do produto), porém distinguem-se destes pela relação estabelecida entre o objeto e o mundo externo. Isto significa dizer que no caso dos valores críticos é preciso estabelecer um referencial norteador externo por meio de questionamentos como: um televisor é resistente e para que finalidade? um automóvel tem quatro portas para qual uso?

Os valores utópicos, em oposição aos práticos, caracterizam-se por elementos que transcendem o produto; os elementos que regem o utópico vão além dos valores práticos: estão referendados pelos valores de base, isto é, pelos sentidos que representam um discurso ideológico ético e moral como liberdade, justiça, responsabilidade, cidadania, felicidade, sucesso, progresso etc. Nesse caso, há uma grande distância entre a produção de sentidos e o valor de uso do produto. Diferentemente dos valores práticos, os sentidos expressos pelos produtos não representam sua funcionalidade ou competência técnica; ao contrário, fazem um discurso de preocupação, comprometimento e cumplicidade com o meio social e cultural dos indivíduos. Esse tipo de discurso se aproxima do que os especialistas de marketing denominam marketing social. Por meio de atividades socioculturais - patrocínio de eventos culturais (concertos musicais, cinema, teatro, esportes...), apoio a campanhas sociais (campanha do agasalho, projeto de alfabetização, distribuição de alimentos em comunidades pobres...) - as empresas exploram os sentidos de preocupação com questões coletivas para vinculá-las aos produtos por ações comunicacionais no composto promocional do marketing. E por outro lado, na produção de sentidos dos valores utópicos, em conjunto com os lúdicos, nota-se que a utopia se

Revista Administração em Diálogo Programa de Estudos Pós-Graduados em Administração Pontifícia Universidade Católica de São Paulo 
transfere das questões coletivas para as individuais, ou seja, a felicidade e o progresso neste caso constroem-se no plano das conquistas individuais e não mais das coletivas como apontamos anteriormente.

Por fim, há os valores lúdicos, que se contrapõem aos valores críticos. Sua relação é de aproximação aos objetos e não de distanciamento, como é como caso dos valores críticos. No caso dos valores lúdicos, a relação dos indivíduos com o uso dos produtos (crítico) é permeada por apelos sociais e psicológicos (status, ego, amor, felicidade, beleza...), que produzem uma sensação lúdica - dão cor, forma, sentimentos, enfim, vida aos objetos. Um bom exemplo desse tipo de discurso são as campanhas promocionais de cervejas, que exploram o humor, a sensualidade e a virilidade, como elementos de sedução para o consumo da bebida.

A partir destes conceitos, Semprini (1995) propõe quatro quadrantes identificados como missão, projeto, euforia e informação (Mapeamento 2) -, com os quais procurou refinar sua ferramenta de análise do discurso do marketing da marca. Os nomes dados aos quadrantes tentam contemplar estilos de vida que correspondem aos valores de consumo desses quadrantes.

\section{Mapa Semiótico do Valores de Consumo}

\footnotetext{
Revista Administração em Diálogo

Programa de Estudos Pós-Graduados em Administração Pontifícia Universidade Católica de São Paulo
} 


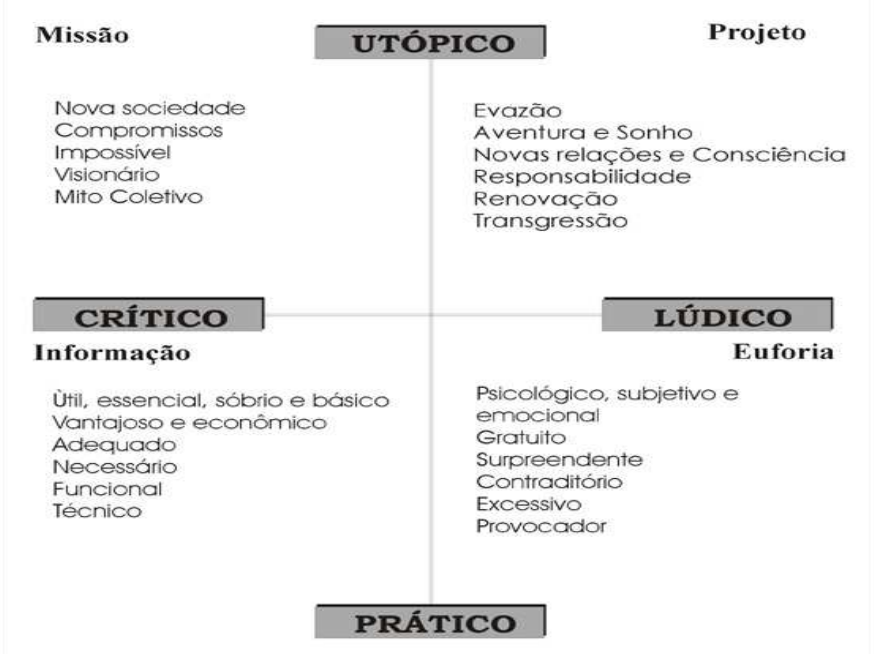

MAPEAMENTO No. 2

Fonte: Matriz sintética do mapeamento dos valores de consumo. (SEMPRINI: 1995, p. 124/130).

Dito isto, recorremos as matriz semiótica de Semprini (mapeamento 2) para verificarmos o processo de construção das marcas do editorial das capas das revistas Carta Capital, Veja, Época e RAE . Essa escolha não é aleatória. Procuramos identificar um produto polêmico quanto ao uso de técnicas de persuasão do consumidor. Digo "polêmico" por se tratar de um "produto" que a priori carrega toda uma expectativa de imparcialidade em seus conteúdos. Revistas, jornais, livros, entre outras formas de disseminação do conhecimento, muito mais do que promover o entretenimento, têm como objetivo implícito estimular a construção de uma sociedade mais esclarecida sobre aspectos políticos, econômicos, sociais, científicos, culturais etc.

A influência das técnicas de marketing nos discursos editoriais das capas das revistas é notável. Basta verificarmos os anúncios publicitários em outdoors, pôsteres nas bancas de jornal e anúncios internos das próprias revistas para observarmos que o discurso editorial da capa, a marca, é parte do processo de sedução e persuasão dos consumidores. A capa funciona como uma espécie de embalagem contendo textos, imagens e cores que produzem sentidos nos imaginários dos leitores.

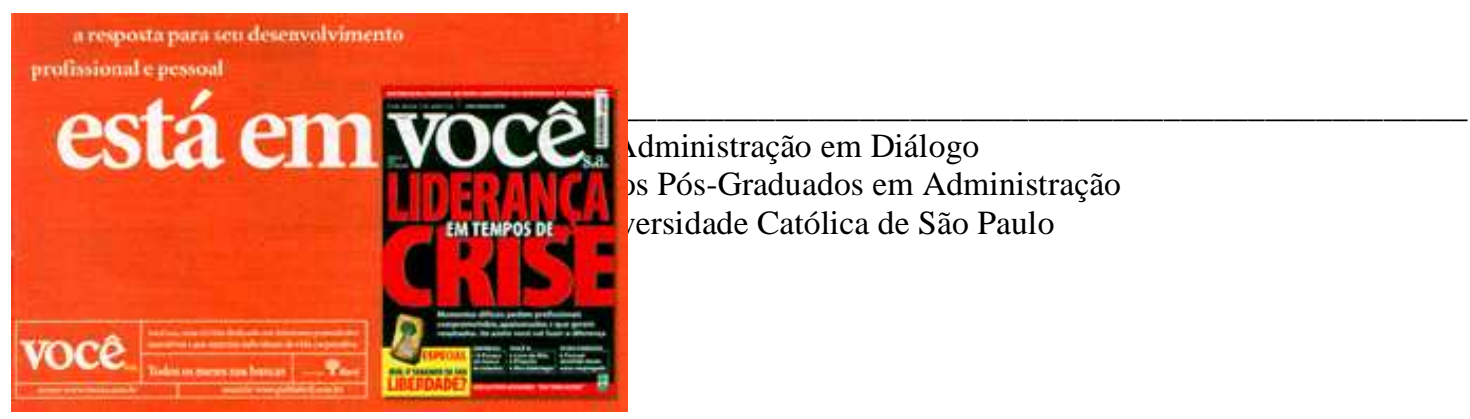


As inserções de anúncios em rádios, televisão, serviço de telemarketing entre outras constituem também importantes ações mercadológicas do marketing editorial, que junto à estratégia de marketing da capa formam o composto mercadológico em que as ações comunicacionais combinam-se de maneira harmônica.

O anúncio publicitário da revista Você s.a. ilustra bem como o marketing da marca articula habilmente as frases de impacto com as capas, potencializando a estratégia de promoção: "a resposta para seu desenvolvimento profissional está em" "Você s.a. Liderança em tempo de crise".

Fonte: Revista Exame 09/06/02 ed. 757

\section{A praxis do marketing da era da comunicação}

O quadrante da missão (mapeamento 2) inspira uma produção de sentidos atinentes ao mundo do indivíduo visionário com seus valores ancorados nas questões sociais coletivas. São sentidos ligados a sentimentos utópicos, ao desejo de um mundo melhor, apoiados na crítica consciente dos problemas sociais (pobreza, desigualdade, violência, racismo...). A capa 1 da Carta Capital, traz no seu discurso editorial como principal manchete a frase: "Universidades/Mais vagas. Para ricos/Apesar da expansão, o ensino superior brasileiro torna-se cada vez mais elitizado", em que se nota a preocupação com a educação e, mais do que isso, que invoca a desigualdade de maneira provocativa. A mensagem assegura a luta por melhores condições de vida para os cidadãos: a chamada reconstitui a posição ricos versus pobres. O tom é de questionamento e reflexão, típicos do cidadão com valores utópicos, idealistas. A foto ilustra as preocupações comunitárias. A inclusão nas Universidades púbicas passa por movimentos coletivos. Na parte superior esquerda, duas chamadas reforçam essa idéia: "Pé no freio: a indústria engaveta novos projetos" e "Índia X Paquistão: cresce o risco de guerra nuclear". O discurso em torno de preocupações sociais é evidente: sem educação, os projetos industriais param e a desigualdade favorece as guerras e os conflitos. No entanto, o lúdico adentra a estética comunicativa: expressões coloquiais e telegráficas como "pé no freio" e "Índia X Paquistão" (lembrando um jogo de futebol, por exemplo), dão mais leveza à linguagem. Um outro elemento que 
caracteriza fortemente o discurso missionário das capas da Carta Capital é a constituição dos atores que comunicam as temáticas. Estes são indivíduos do cotidiano (não se explora a comunicação por meio de personagens midáticos). Trata-se de uma fotografia real de um fato ocorrido em um determinado local, com alunos das universidades. As representações podem ter diversos significados: a foto da capa 2 por exemplo, ilustra a exclusão do consumo, a violência urbana ou as duas coisas.

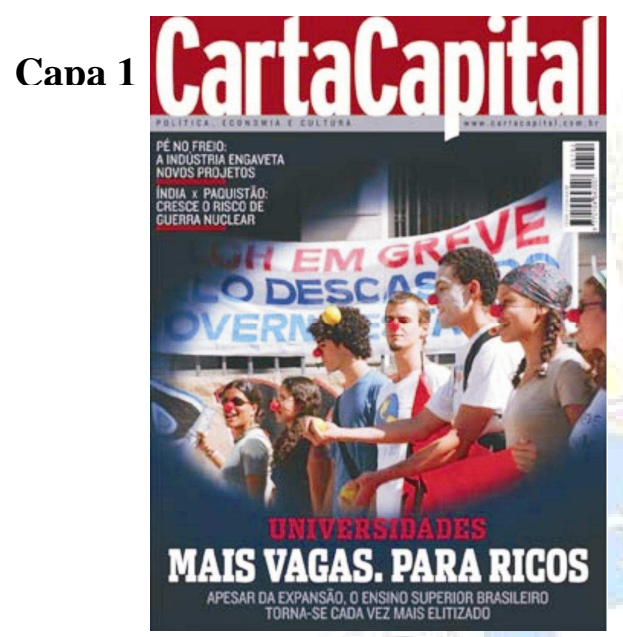

Fonte: Revista Carta Capital 05/06/02 ed. 192
Cana 2

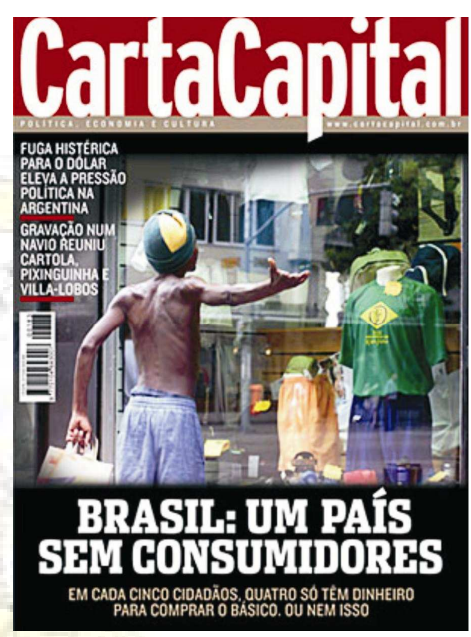

Fonte: Revista Carta Capital 03/04/02 ed. 183

Na capa 2, a manchete principal - "Brasil: um país sem consumidores/Em cada cinco cidadãos, quatro só têm dinheiro para comprar o básico. Ou nem isso" - destaca os temas de exclusão e pobreza. A miséria, a violência, a desigualdade e a intolerância ligam-se a questões de exclusão pelo racismo. As demais chamadas na parte superior esquerda da capa 2 - "Fuga histérica para o dólar eleva a pressão política na Argentina" e "Gravação num navio reuniu Cartola, Pixinguinha e Villa-Lobos"- têm cunho questionador, sempre sobre o pano de fundo das questões sociais. Todo o discurso da Carta Capital se legitima por informações práticas (presentes no repertório do crítico). Ressalte-se que, em geral, esses discursos pressupõem um repertório de conhecimentos políticos, culturais, econômicos e sociais acima da média da sociedade brasileira. Isso reforça a opção por valores de consumo ancorados em valores utópicos e críticos, ou seja, missionários.

Revista Administração em Diálogo 
No quadrante do projeto (mapeamento 2), os valores utópico e lúdico forjam um perfil centrado no individualismo e no hedonismo. Diferentemente do quadrante do missionário, o lado utópico subsiste pela utopia da busca da felicidade, do sonho de um mundo melhor, da consciência sobre a riqueza e pobreza, mas tudo isso em benefício próprio. O lúdico tem uma grande influência no consumo desse indivíduo. É pelas emoções que se chega ao prazer, à aventura, às novas relações. A psicologia tem uma interferência significativa no projeto de dar cor, alma, vida aos sonhos individualistas e hedonistas desse cidadão. $\mathrm{Na}$ perspectiva de uma hierarquia organizacional, ele preenche as exigências profissionais do gerente que executa a doutrina preconizada pelo líder maior (o missionário). Centrado que está em seus prazeres pessoais (amor, sexo, aventura etc.), o olhar desse cidadão sobre suas atividades cotidianas focaliza-se no seu $e u$, e toda sua energia física e mental é orientada para isso. De modo prático, esse indivíduo tende a ser um excelente cumpridor de tarefas, colhendo resultados eficazes; os possíveis desdobramentos de suas conquistas são secundários.

O mundo pactuado e prometido aos participantes (fornecedores e usuários de bens e serviços) desse quadrante carrega a utopia do missionário, mas com uma conduta individualista. A preocupação com a felicidade, os sonhos e os desafios é individual, ao contrário do mundo do missionário, norteado pelo mito do coletivo. O lado lúdico desse universo advém das relações psicológicas e físicas que se estabelecem com o corpo, com os prazeres da vida, com as aventuras e com as novas relações afetivas que a vida pode proporcionar.

Revista Administração em Diálogo 


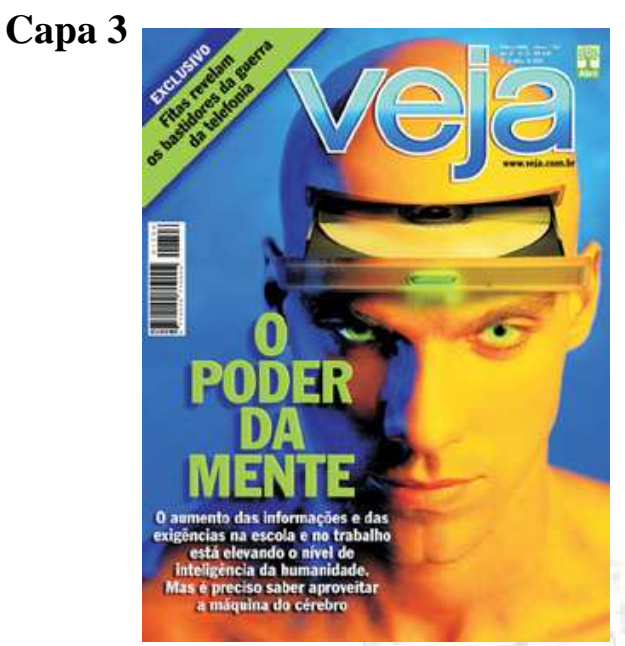

Fonte: Revista Veja 26/06/01 ed. 1706

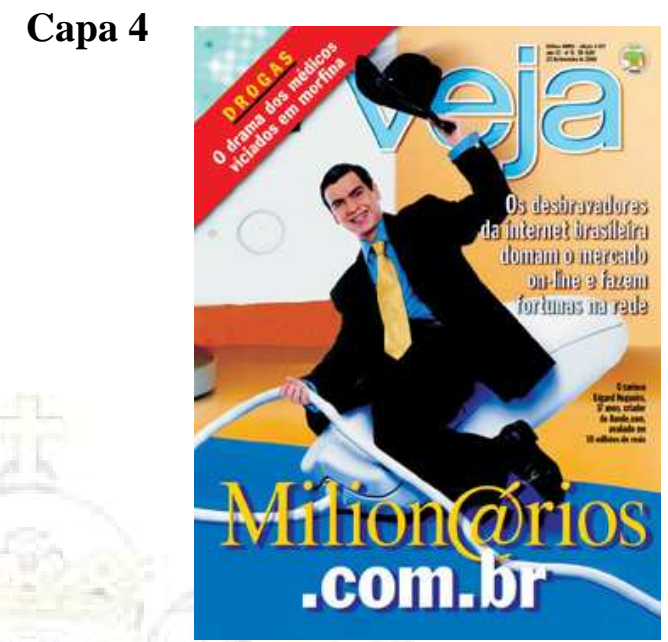

Fonte: Revista Veja 23/02/2000 ed. 1637

As manchetes principais das capas 3 e 4 - "O poder da mente" e "Milionários.com.br" são frases curtas que trazem temas de poder típicos do mundo do projeto.

A capa 3 traz um discurso afirmativo, simplificado para uma temática complexa que envolve a ciência cognitiva, a educação e a economia. A revista faz um recorte de conteúdos na construção do discurso que seduz os interessados em resultados rápidos. A simplificação da questão elimina a discussão no âmbito coletivo que exige uma análise mais aprofundada. A chamada superior do lado esquerdo da Capa "Exclusivo" confirma o jogo de sedução que Veja trabalha, isto é, apenas você, leitor da Veja, terá acesso aos bastidores da guerra de telefonia. Da mesma maneira a capa 4 traz a figura do novo executivo que acessou on-line o sucesso e a felicidade por meio da fortuna de 10 milhões de reais que o novo sistema de comunicação, a internet, proporciona.

No pólo oposto ao de Carta Capital, Veja traz questões que dizem respeito diretamente à vida pessoal dos indivíduos. E mais, nas matérias das manchetes, o discurso construído trata mais profundamente dos temas, e vem acompanhado propostas em formato de manual para a consecução do desafio. Veja sabe como utilizar o poder da mente e o 
caminho para tornar-se um milionário. As fotos nas capas também sugerem o estilo de vida do projeto. A imagem futurista (o drive do super computador e o penetrante olhar laser) do "poder da mente" não deixa dúvidas de que a força está dentro de cada um. Finalmente, a atitude lúdica do milionário surfando sobre sua riqueza, parece seduzir a todos que buscam realizações, físicas, espirituais e individuais.

No quadrante da euforia (mapeamento 2) entre os eixos lúdico e prático denota, a priori, uma contradição. Como algo pode ser prático (funcional, objetivo, técnico etc.) e, ao mesmo tempo, lúdico (emocional, hedonista, irracional etc.)? Semprini responde: "Estaríamos diante da cultura do produto 'inútil', porém que se adora: pouco funcional, porém muito divertido etc.” (SEMPRINI: 1995, p. 129.)

Trata-se de ler na euforia seu lado psicológico, tranqüilizador, reconfortante, alegre, positivo, que permite imprimir ao objeto ou ao serviço cor, alegria, diversão, aconchego, sensualidade, potência, além de suas características funcionais. Esse mundo (euforia) é muito vivo nos valores de consumo da grande maioria dos brasileiros - o humor, a sensualidade, o chocante, o provocativo são valores de consumo ligados à euforia, e impregnam muitas campanhas publicitárias brasileiras contemporâneas. Um bom exemplo é o discurso preconizado pelas campanhas publicitárias de cervejas, refrigerantes, cigarros e automóveis que de maneira geral são permeados pelos valores lúdicos (sensualidade, amizade, afeto, diversão entre outros) presentes no quadrante da euforia.

Revista Administração em Diálogo 


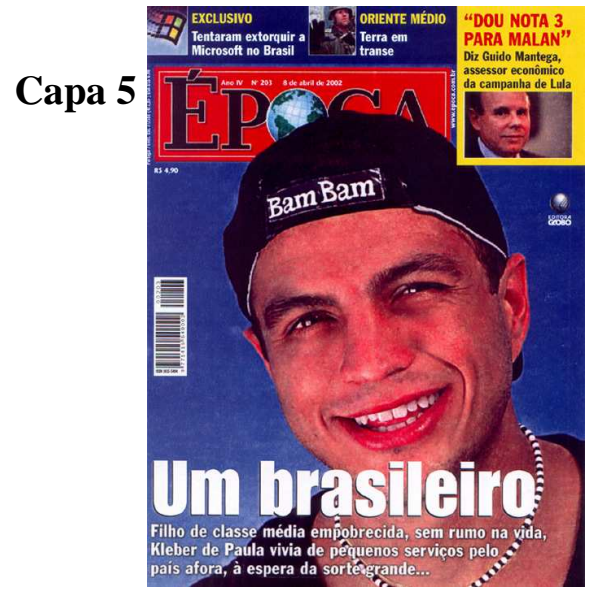

Fonte: Revista Época 08/04/02 ed. 203

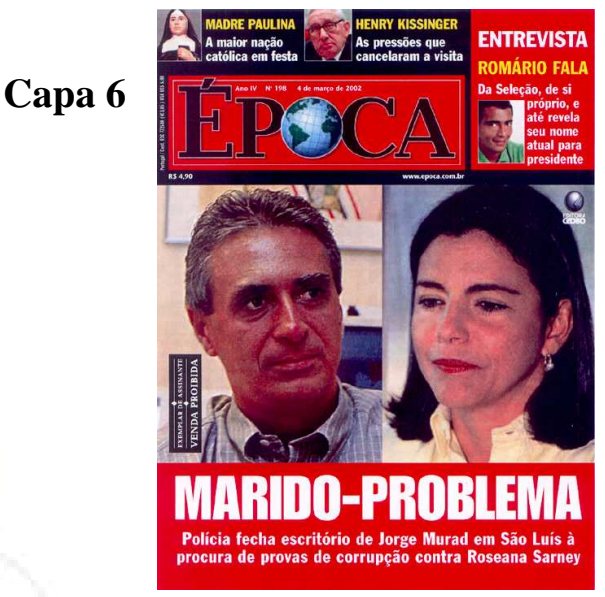

Fonte: Revista Época 04/03/02 ed. 198

A capa 5, por exemplo, a imagem de Kleber - "Um brasileiro"2 - produz o sentido do divertido e, ao mesmo tempo, explora o lado psicológico do "batalhador" de origem humilde que "venceu os desafios da vida". Até mesmo a disputa presidencial ganha um cunho eufórico. Na capa 6, as fotos de Roseana Sarney e de Jorge Murad, com a frase "Marido problema", levam a eleição presidencial para a temática das relações familiares: o Planalto entra "nas relações cotidianas de uma família". Essa aproximação com o âmbito familiar é típica dos valores lúdicos de consumo, que trabalham com relações emocionais e intensas, como é o caso da família.

Note-se também que, nas capas da revista Época, a disposição das fotos e as cores são muito mais eufóricas do que nas das outras três revistas analisadas - a estética das capas produz um sentido de cotidianidade, suscitando aspectos afetivos, familiares e emocionais. Nesse quadrante, a estética contribui de maneira relevante para destacar a atmosfera do colorido, do mágico, do moderno etc., potencializando o sentido da euforia.

De maneira oposta à revistas Carta Capital, os personagens das capas de Época são pessoas conhecidas na mídia de massa ( Bam Bam, Romário, Madre Paulina, Roseana

\footnotetext{
${ }^{2}$ Trata-se do vencedor do reality show veiculado pela Rede Globo, Big Brother Brasil I.
} 
Sarney) que estimulam emoções de amor, ódio, alegria, tristeza... no leitor. Nota-se que o espaço para o leitor refletir sobre as manchetes torna-se limitado; a "praticidade" dos fatos norteada pelo lúdico colaboram para atenuar questões profundas do cotidiano da sociedade. A economia, a religião, e o esporte são representadas por meio de expressões que podem trazer medo ou segurança. O importante é despertar no leitor os sensórios do afeto, do medo, do amor, do ódio, enfim, os comportamentos emocionais do indivíduo.

Finalmente, o quadrante da informação (mapeamento 2) representa a convergência dos valores de consumo práticos e críticos. O quadrante de informação opera numa lógica racional. Trata-se de enfatizar aí as características do produto ligadas a utilidade, vantagem, preço, garantia, qualidade, durabilidade funcionalidade etc. Ler o quadrante de informação é pensar a sociedade de maneira calculista e objetiva, no que se refere ao consumo. Ou seja, é conceber que o perfil desse consumidor está imune às interferências sociais e psicológicas do consumo. A priori, pode-se imaginar que apenas os produtos de primeira necessidade são objetos de um discurso ancorado na informação. Entretanto, apesar de o quadrante de informação não usar recursos subjetivos (psicológicos e sociais) na construção do seu discurso, devemos nos lembrar de que o caráter de sedução não passa necessariamente por esse recorte; diversos produtos considerados supérfluos (eletrônicos, eletrodomésticos, móveis etc.) têm seu discurso propagandístico forjado a partir de valores desse quadrante. Empresas como a Sony, a Philips e a CCE fazem campanhas de marketing focando as características técnicas dos produtos. A bem da verdade, não se trata de valores de consumo dos produtos, mas dos consumidores. Assim, há que se considerar que determinados indivíduos podem ser seduzidos por um discurso ancorado em dados técnicos sem que sejam considerados "alienígenas".

Uma análise das capas da Revista de Administração de Empresas (RAE) da Fundação Getulio Vargas, mostrará a racionalidade (a publicação não traz nem sequer uma foto) de um discurso ancorado em valores de consumo da informação.

Revista Administração em Diálogo 


\section{Capa 7}

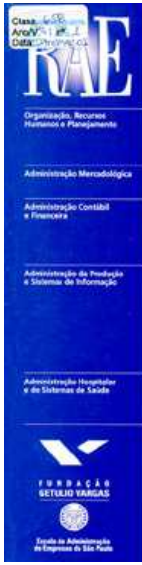

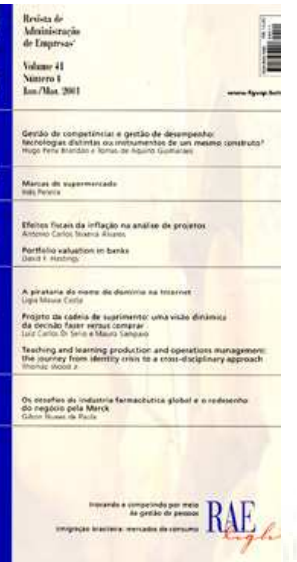
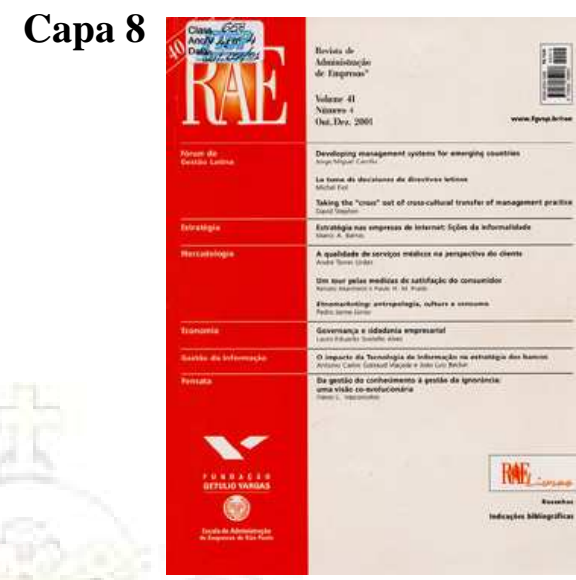

Fonte: Revista RAE Jan./Mar. 2001 Vol. 41 n.1 Fonte: Revista RAE Abr./Jun. 2001Vol. 41 n.2

As capas 7 e 8 trazem informações escritas sem o uso de manchetes ou fotos. Os textos seguem o formato de um índice para facilitar a leitura. $O$ fato da revista não apresentar fotos e cores fortes nas capas não significa que não sejam utilizados recursos estéticos no processo de sedução do consumidor. O não uso desses recursos caracteriza, por si só, uma estética alinhada com esse comportamento de consumo. Esse tipo de consumidor pertence a um mundo sóbrio, técnico, que lhe oferece o necessário para seu uso, de forma adequada e econômica.

As chamadas, por exemplo, da capa 7: "Gestão de competências e gestão de desempenho: tecnologias distintas ou instrumentos de um mesmo construto?"; "Marcas de supermercado"; "Os desafios da indústria farmacêutica global e o redesenho do negócio pela Merck", comunicam o produto (textos) e em alguns casos apresentam um tom de espírito crítico. Porém, trabalha-se com uma racionalidade e praticidade que não explora outro sentido senão o de comunicar ao leitor a discussão que será desenvolvida na matéria. A preocupação é orientar a leitura de maneira organizada e linear dos artigos publicados na revista. O sentido da comunicação é informativo, sem explorar os valores de base (utópicos e lúdicos), e sim os valores práticos do uso da informação contida nas discussões e críticas que norteiam as temáticas.

Revista Administração em Diálogo 
Nota-se também que a ausência de imagens colabora para a racionalidade que este formato de comunicação exige. Porém, vale destacar que este tipo de comunicação não impede o uso de imagens; a diferença é que neste caso as imagens e textos não devem produzir outro sentido que não aqueles ancorados nos valores de uso, ou seja, práticos e críticos.

\section{Considerações finais}

O mapeamento dos valores de consumo ilustrados na análise das capas da Carta Capital, Veja, Época e RAE ilustra os mecanismos de construção do marketing da marca presente no discurso editorial. O processo comunicacional das capas é norteado pela produção dos sentidos e pela tecnologização do discurso, forjando estilos de vida e experiências que despertem e estimulem os indivíduos a participar de um determinado conceito de mundo.

Em síntese, as capas da Carta Capital executam sua estratégia de marketing da marca por meio do seu discurso editorial, publicando fatos que remetem o leitor à interlocução da notícia e outros conhecimentos sociais, culturais, econômicos, políticos etc., presentes no repertório do leitor. As revistas exigem do leitor um aparato de conhecimento acerca das questões que influenciam a vida coletiva.

O discurso editorial das capas da Veja por sua vez opera através da estratificação social em que fala Baudrillard (1995, p. 78), marcando-se fortemente uma divisão de classe. Apenas o leitor da Veja teria acesso às verdades preconizadas pela revista. As preocupações temáticas da revista, diferentemente da Carta Capital, se fixam no indivíduo e não no coletivo. O mundo Veja é o espaço do sucesso, do prazer, da competitividade, do narcisismo, enfim, para todos aqueles que desejam o status de pertencer ao mundo dos melhores. Muito embora Veja também realize interlocuções em suas notícias com outras áreas de conhecimento, nota-se que neste caso não se exige do

Revista Administração em Diálogo Programa de Estudos Pós-Graduados em Administração Pontifícia Universidade Católica de São Paulo 
leitor um conhecimento prévio das questões. Veja, num processo de negociação prévio com o seu leitor, apresenta as verdades que reafirmam os discursos do seu público.

De maneira diferente a revista Época se utiliza dos recursos de emoção e afetividade que aponta Packard ${ }^{3}$ (1980) na análise dos estudos de profundidade. Apesar da revista construir uma ligação mais próxima do produto (as notícias) com suas temáticas, o uso de sentidos afetivos e emocionais ganha um espaço significativo na persuasão dos leitores. Os temas são sensacionalista e remete a experiências cotidianas do leitor nas suas relações familiares, amorosas, de trabalho, isto é, a política, a economia e os problemas sociais são tratados de maneira simplificadora e emotiva.

Por fim, a revista RAE mantém uma ligação muito próxima do produto (a notícia) no processo de comunicação. Neste caso o leitor recebe as notícias de maneira simples e direta. O sentido é prático e objetivo, não sendo utilizados recursos culturais, sociais e psicológicos na produção de sentidos do discurso editorial. O limite para a sedução é o de instigar o leitor para as temáticas propostas e o fundo crítico que elas podem produzir. Esta maneira de comunicação é a que mais se assemelha dos primórdios das estratégias de marketing, ou seja, são apenas comunicados os benefícios e competências dos produtos; o sentido é deixado para o consumidor e a interferência do produtor no processo de sedução é quase nula.

A análise do marketing da marca presente no discurso editorial das capas acena para um sistema de manipulação dos valores de consumo dos indivíduos, próprio do marketing contemporâneo. Os recursos comunicacionais do design editorial das capas são os mesmo praticados nas campanhas de marketing. Desta maneira, a informação contida nas capas (o produto das revistas) torna-se uma mercadoria como outra qualquer, sujeita às mesmas técnicas de persuasão e sedução de um bem de consumo.

\footnotetext{
${ }^{3} \mathrm{O}$ jornalista Vance Packard na década de 70 faz uma dura crítica a publicidade apontando para as técnicas de "estudos de profundidade" que psicólogos e antropólogos realizavam para entender e manipular o comportamento do consumidor.
}

Revista Administração em Diálogo 
A transição do marketing da produção de bens e serviços para o marketing da marcacultural modifica a relação de competitividade entre as empresas. Com a tendência da comoditização da produção e da cultura, a concorrência se desloca para o mundo prometido no lugar dos bens ou serviços oferecidos. A eficiência reside em conseguir forjar mundos mais congruentes com o imaginário de cada público. Nessa nova forma de construção do sistema de circulação de mercadorias, há que se construir, no imaginário dos indivíduos, o mundo desejado. Por meio da construção de atores, espaços, tempos, relações e paixões, instaura-se uma encenação cuja porta da entrada são os atributos culturais vinculados a determinado produto, que constitui identidades.

Os fundamentos da tecnificação do discurso do marketing da marca apresentados por Floch e Semprini são fortíssimas evidências do esvaziamento dos conceitos de administração de marketing. Isso não significa que seus elementos não são mais parâmetros para administrar o marketing, mas que há que considerar a renovada importância dos signos culturais e dos processos de significação nessa administração, ou seja, as estratégias discursivas e comunicacionais. O desenvolvimento do produto, a formação de preço e a distribuição ganham, como elemento determinante na construção de suas ações, o tratamento da tecnificação dos signos culturais. Os bens ou serviços são permeados por valores do repertório dos diversos agentes envolvidos no processo de construção do produto. Forja-se um discurso coerente para cada público. A necessidade ou o desejo se deslocam do produto para um discurso sobre um mundo adequado aos mitos e crenças dos indivíduos. Da mesma maneira, o preço e a distribuição têm como foco não mais os bens ou serviços, e sim o mundo ensolarado do consumidor que precisa do protetor solar; o mundo pós-moderno, complexo, violento, individualista e produtivo do consumidor que vai adquirir as últimas novidades tecnológicas, ou modesto, cooperativo, simples e bucólico daquele que procura uma casa de campo.

Portanto, as discussões aqui desenvolvidas trazem evidências de que o marketing contemporâneo cada vez mais se desloca da produção fabril para a dos sentidos afetivos, sociais e culturais, ou seja, a gestão mercadológica depende cada vez mais da 
tecnologização do discurso, a marca. Os impactos dessa mudança atingem todas as esferas - da produção de um televisor a um tratamento médico. As mesmas técnicas de marketing são aplicadas em todos os setores da sociedade: alimentação, bens industriais, saúde, lazer, educação, finanças etc. Os alimentos do supermercado Pão de Açúcar pertencem ao "lugar de gente feliz", o automóvel da Fiat Stilo "é para que tem estilo", a educação do Centro Universitário Ibero-Americano é para "quem tem luz própria e é o astro principal”, o cartão de crédito Bradesco Visa Infinite afirma que "o infinito é um lugar para poucos", o Bank Boston é para "simplesmente primeira classe". Enfim, em níveis diferentes, todo o processo de sedução é deslocado da finalidade de uso do produto.

\section{Referências}

BARROS, D. L. P. de. Teoria semiótica do texto. São Paulo: Ática, 4 edição, 2000.

BAUDRILLARD, J. A sociedade de consumo. Rio de Janeiro: Edições 70, 1995.

FAIRCLOUG, N. Discurso e mudança social. Brasilia: UNB, 2001.

FIORIN, J. L. Elementos de análise do discurso. São Paulo: Contexto, 2000

FLOCH, J. M. Semiótica, marketing y comunicacion. Barcelona: Paidós, 1993.

Sociossemióticas. São Paulo: Edições CPS, 2001.

PACKARD, V. Nova técnica de convencer: persuasão ocultal domínio do público pelo subconsciente/ sugestão subliminar. São Paulo: IBRASA, 5 edição, 1980.

RIFKIN, J. A era do acesso. São Paulo: Makron Books, 2001.

SANDRONI, P. Novíssimo dicionário de economia. São Paulo: Best seller, 6 edição, 2001.

SEMPRINI, A. El marketing de la marca. Barcelona: Paidós, 1995. 